\title{
A Longitudinal Study of Total Body Potassium in Normal Children
}

\author{
MARGARET A. FLYNN, (11) JACK CLARK, J. C. REID, AND GERALD CHASE \\ Departments of Nutrition, Community Health, Animal Husbandry, and Statistics, University of Missouri-Columbia, \\ Columbia, Missouri, USA
}

\section{Extract}

Most investigators studying changes in body composition during growth agree to the desirability of having longitudinal data. A group of 110 boys and 126 girls, studied annually for $4-5$ years with 880 measurements of total body $\mathrm{K}$ in a $2 \pi$ liquid scintillation whole body counter, had total body $\mathrm{K}$ vs. height and total body $\mathrm{K}$ vs. weight data that fit previously described regression lines.

\section{Speculation}

Given an adequate diet and environment, children increase their total body $K$ in a predictable amount in reference to skeletal growth.

In order to derive normative data that would reflect physiologic and endocrinologic changes of normal growth, we measured height, weight, and total body potassium (K), by whole body counting, in a cross-sectional study of 462 children aged 3-18 years (2). About half of the original study group comprise a cohort that has been followed for up to 5 years. The objectives of the study reported here are $(l)$ to show that total information collected to date is in good agreement with the regression lines for total body potassium reported by Flynn et al. (2), and (2) to characterize the longitudinal behavior of the individual members of the cohort as to their stability with respect to those regression lines. Most investigators studying changes in body composition during growth agree to the desirability of having longitudinal data, in which the same children are studied repeatedly over a period of years (6-8).

\section{METHODS}

The 236 subjects were 110 boys and 126 girls aged 3-18, who were studied annually over a period of $4-5$ years. There were 880 different measurements, 434 of them in girls and 446 in boys. The first measurement for each child has already been reported in the previous cross-sectional study of 462 children (2). Recruited by informed consent, the children came from "middle socioeconomic background" and were in apparent good health, free of known acute or chronic disease. More than $90 \%$ of the children were within the 16th and 84th percentiles of weight of the Iowa Growth Charts and within 1 SD of height. The rest were within the 5th and 95th percentiles.

Total body potassium was calculated from whole body counting of $\gamma$ emissions of naturally occurring ${ }^{40} \mathrm{~K}$, using the University of Missouri's $2 \pi$ liquid scintillation counter. Calibration curves for ${ }^{40} \mathrm{~K}$ were determined by counting a known amount of $\mathrm{KCl}$ in water in plastic phantoms and ascertaining the efficiency of various sizes and shapes. Daily ${ }^{40} \mathrm{~K}$ counts of three female and three male adults of various sizes and shapes for 10 days and of two adults over a period of 4 years have shown a coefficient of variation of $2.5 \%$. The children, dressed in hospital gowns, lay prone on a hospital cart centered under the counter, which was lowered to 1 inch from their buttocks. Three 5-min counts were taken and the average of before and after 5 min background counts was subtracted. The net counts per min were corrected for an efficiency factor based on body weight derived from the previously cited calibration curve. Standing height was measured to the nearest centimeter against a calibrated wall, using a headboard for horizontal fit. Weight was measured on a laboratory scale to the nearest $100 \mathrm{~g}$ interval.

\section{RESULTS}

The data were analyzed using the University of Missouri IBM $370 / 168$ computer. Some of the analyses utilized programs available in the SAS package. To illustrate the agreement of the longitudinal observations with the original data presented in the study of Flynn et al. (2), all of the obervations (original and follow-up) are plotted in Figures 1 and 2. Referring to these figures, a good agreement is obvious. In order to give additional insight into the distributions, the data plotted in Figures 1 and 2 have been summarized in Table 1. An example of the calculations in Table 1 is given by one visit by an 11 -year-old girl whose height was $145 \mathrm{~cm}$ and who had a TBK of $71 \mathrm{~g}$. The study of Flynn et al. (2) using the fitted line for the natural logarithm of total body $\mathrm{K}$

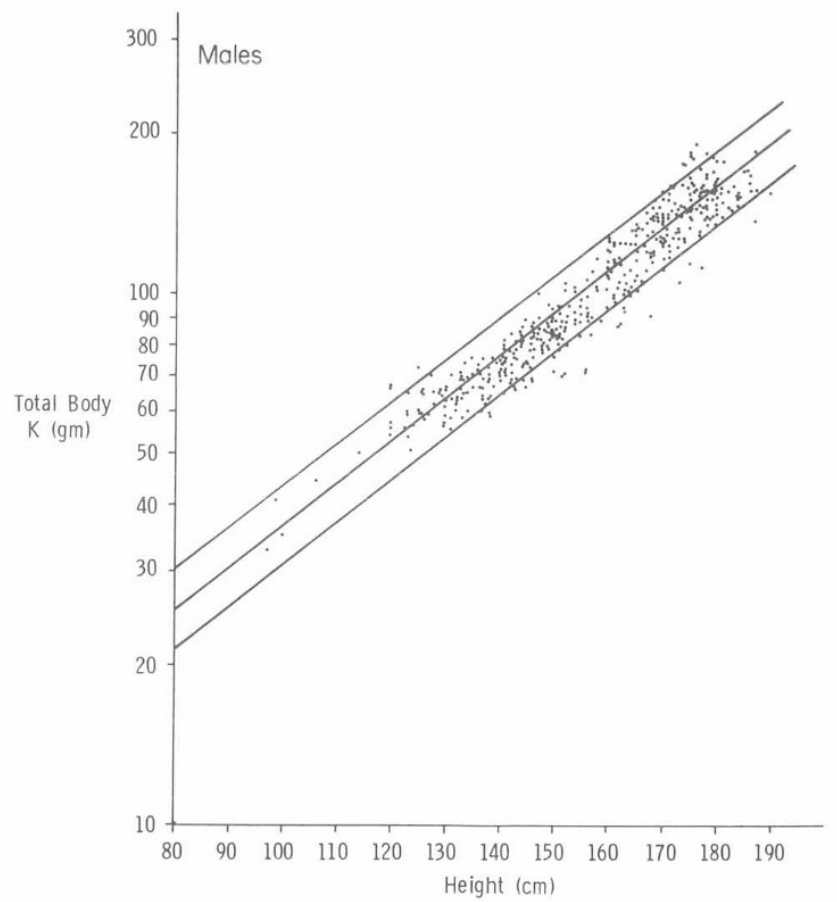

Fig. 1. Relationship between height and total body potassium in boys. Annual measurements of the same 110 boys over a 4-5-year period compared with the regression lines for the mean and the tolerance region for $68 \%$ of the population for the In of total body potassium vs. height for 232 boys aged 3-18 years from the data of Flynn et al. (2). 
for girls taller than $135 \mathrm{~cm}$, gives $2.574+(0.01215)(145)=4.336$. The natural logarithm of $71[\ln (71)]$ is 4.263 . The actual observations 4.263 thus falls below the fitted line, 4.336. In order to compare this observation with others for the same girl, we express it in terms of number of standard deviations from the line. Thus, using the 0.09 estimate of the standard deviation from the previous study (2), we get $(4.263-4.336) / 0.89=-0.8$ I SD from the line. The minus sign indicates that the observation was below the line. Therefore, this observaton is in the category " $-1 \sigma$ and $0 . "$

The age at initial observation, number of observations, and deviation of follow-up differ between members of the cohort. This heterogeneity makes it difficult to summarize the longitudinal behavior. Using the calcuations described for Table 1, longitudinal position relative to the lines relating height and total body $\mathrm{K}$ from the previous study (2) is characterized in Table 2. For example, if the initial observation is $-1.40 \sigma$ below the line and the first follow-up is $+2 \sigma$ above the line, the absolute value of the difference is $1.6 \sigma$. Therefore it falls in the category between $1^{1} 2 \sigma$ and $2 \sigma$. It can be seen from Table 2 that the cohort was quite stable relative to the line when the observations were about 1 year apart. Movement more than $1.5 \sigma$ occurred with only $7 \%$ of the cohort.

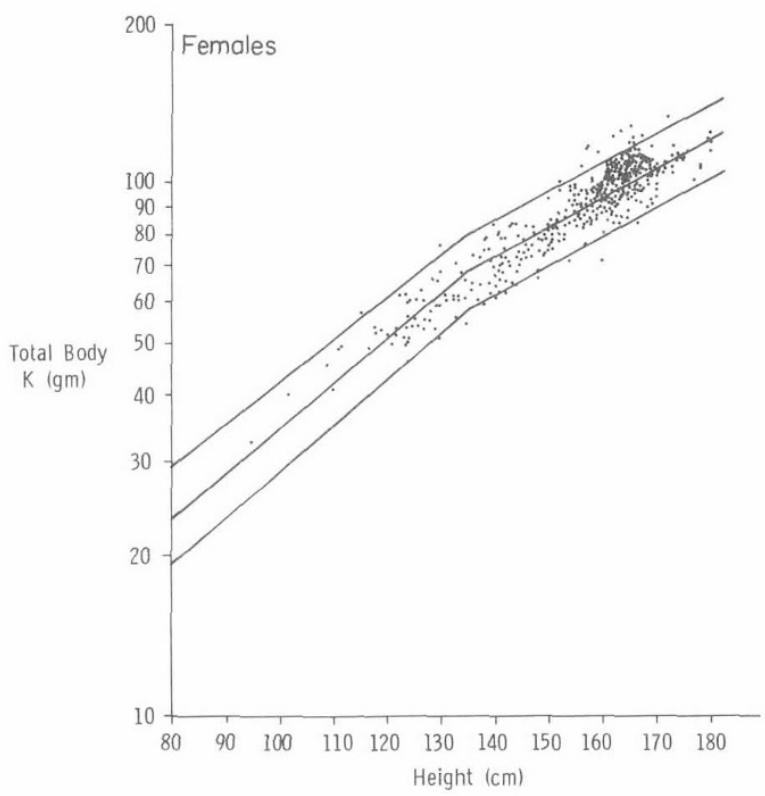

Fig. 2. Relationship between height and total body potassium in girls. Annual measurements of the same 126 girls over a 4-5-year period compared with the regression lines for the mean and tolerance region for $68 \%$ of the population for the In of total body potassium vs. height for 230 girls aged 3-18 years from the data of Flynn et al. (2).
If all of the observations for each subject are used to compute a range (maximum minus minimum), instead of just the first two observations in Table 2, a broader range is of course observed. These calculations give $41 \%$ of the subjects' range less than $1 \sigma$, $42 \%$ between $1 \sigma$ and $2 \sigma$, and $17 \%$ more than $2 \sigma$.

Table 2. Distribution of absolute values of differences between distance from height-K lines for initial and second observations (in $S D$ ) in l-year interval

\begin{tabular}{lrr}
\hline & \multicolumn{2}{c}{ Percentage } \\
\cline { 2 - 3 } Absolute value of difference & $\mathrm{M}$ & $\mathrm{F}$ \\
\hline Less than $1 / 2 \sigma$ & 54 & 51 \\
Between $1 / 2 \sigma$ and $1 \sigma$ & 27 & 22 \\
Between $1 \sigma$ and $1 \frac{1}{2} \sigma$ & 12 & 20 \\
Between $1 \frac{1}{2} \sigma$ and $2 \sigma$ & 4 & 6 \\
Greater than $2 \sigma$ & 3 & 1
\end{tabular}

Greater than $2 \sigma$

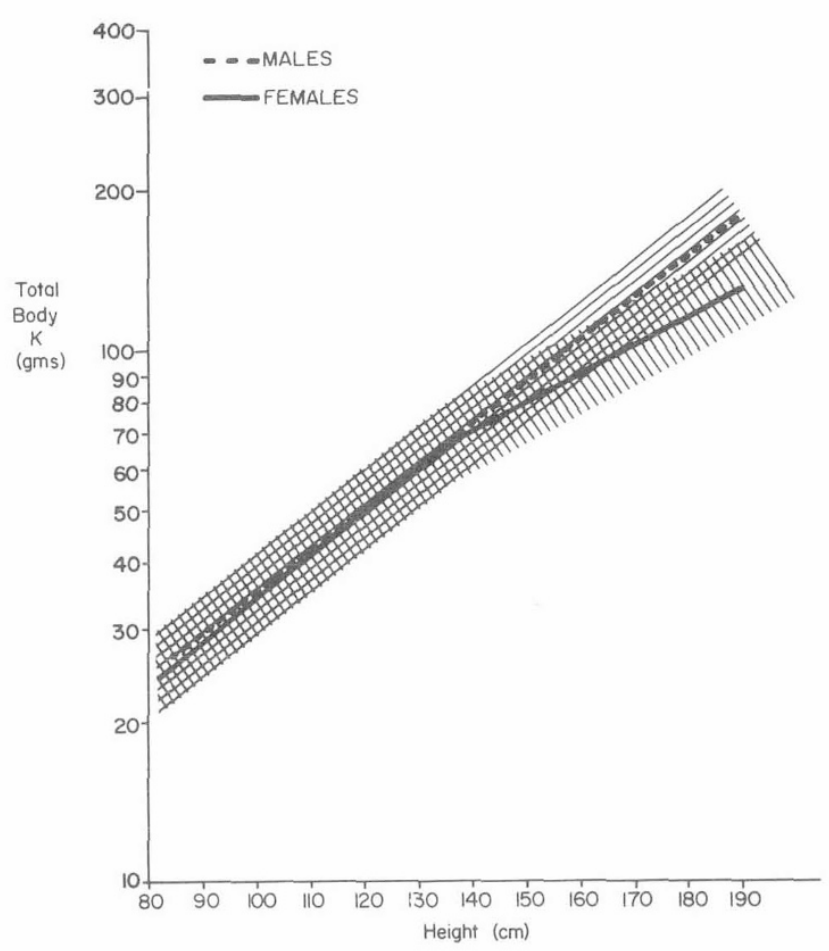

Fig. 3. Regression line for the mean and the tolerance region for $68 \%$ of the population for the $\mathrm{In}$ of total body potassium vs. height for 432 children aged 3-18 years. Data from Flynn et al. (2).

Table 1. Distribution of distances (expressed as standard deviations) from fitted height-K lines for all observations to date

\begin{tabular}{|c|c|c|c|c|c|c|}
\hline \multirow{3}{*}{$\begin{array}{l}\text { Distance of In K from fitted } \\
\text { line expressed as number of SD }\end{array}$} & & & \multicolumn{4}{|c|}{ Female } \\
\hline & \multicolumn{2}{|c|}{ Male } & \multicolumn{2}{|c|}{$\mathrm{ht} \leq 135 \mathrm{~cm}$} & \multicolumn{2}{|c|}{$\mathrm{ht}>135 \mathrm{~cm}$} \\
\hline & No. & $\%$ & No. & $\%$ & No. & $\%$ \\
\hline Less than $-2 \sigma$ & 16 & 3.6 & 2 & 2.6 & 6 & 1.7 \\
\hline Between $-2 \sigma$ and $-1 \sigma$ & 51 & 11.4 & 6 & 7.8 & 27 & 7.6 \\
\hline Between $-1 \sigma$ and 0 & 166 & 37.2 & 25 & 32.5 & 110 & 30.8 \\
\hline Between 0 and $1 \sigma$ & 158 & 35.4 & 30 & 39.0 & 131 & 36.7 \\
\hline Between $1 \sigma$ and $2 \sigma$ & 48 & 10.8 & 11 & 14.3 & 66 & 18.5 \\
\hline Greater than $+2 \sigma$ & 7 & 1.6 & 3 & 3.9 & 17 & 4.8 \\
\hline Total & 446 & 100.0 & 77 & 100.0 & 357 & 100.0 \\
\hline
\end{tabular}




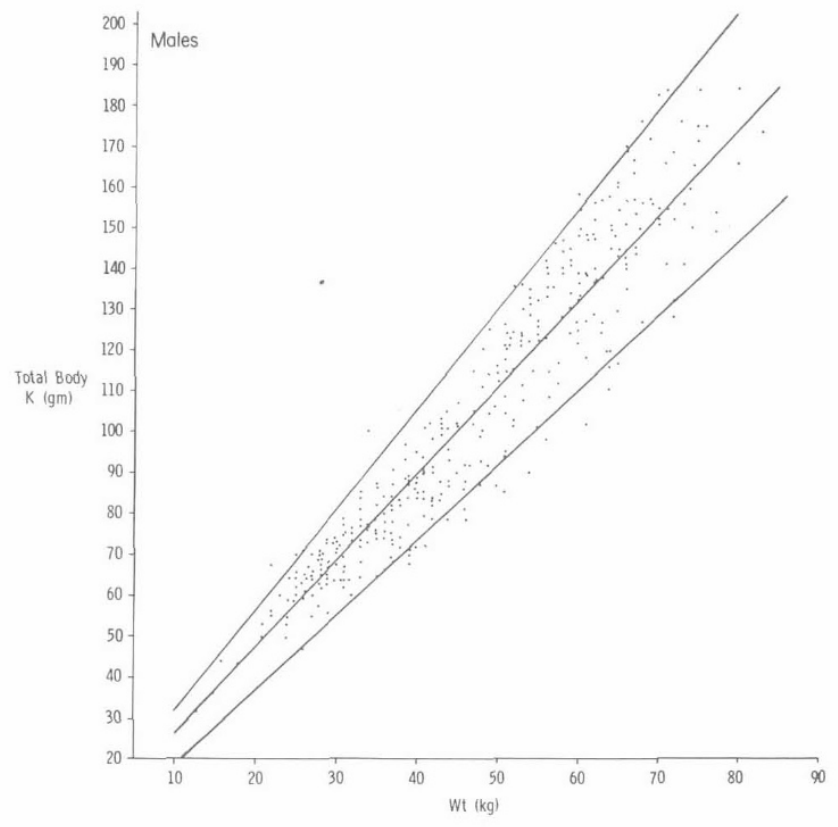

Fig. 4. Relationship between weight and total body potassium in boys. Annual measurements of the same 110 boys over a 4-5-year period compared with the regression lines for the mean and tolerance region for $68 \%$ of the population for total body potassium vs. weight for 232 boys aged 3-18 years from the data of Flynn et al. (2).

\section{DISCUSSION}

This study reveals that measurements for total body $\mathrm{K}$ and height in boys and girls studied longitudinally over a period of $4-5$ years maintain the same regression slope during growth as the slope predicted from a larger number of children studied one time at various ages. Our data and those of other investigators who have studied lean body mass (LBM) derived from ${ }^{40} \mathrm{~K}$ studies agree that LBM is related to stature $(1-5,9)$. Especially in boys, our data show that during normal growth, accretion of total body K occurs in a predictable amount in reference to height gain.

As the children aged the height and total body $\mathrm{K}$ increments did not always remain in the same proportion of deviation from the mean line of our previous study. However, the fluctuations are within acceptable range. These data verify the unpredictability of maturation that occurs during growth, especially in the prepubescent and adolescent stages. In spite of this, the longitudinal measurements of .physiologic growth fit remarkably well the statistical derivations which we previously published: for males, In $\mathrm{K}$ in grams $=1.761+0.0182 \times \mathrm{cm}$ of height and for females, In $\mathrm{K}$ in grams $=1.595+0.01942 \times \mathrm{cm}$ for height $\leq 135 \mathrm{~cm}$, and $\ln \mathrm{K}$ in grams $=2.574+0.01215 \times \mathrm{cm}$ for height $>135 \mathrm{~cm}$. Forbes $(4)$, in a recent report of compilation of body composition data from many investigators, states that stature accounts for variance in LBM (and hence in total K) in both sexes. Some of the girls in our study achieved tallness sooner than others, placing a larger number of them in the greater than $135 \mathrm{~cm}$ group. Total body $\mathrm{K}$ increment accompanied the height increment.

Our present longitudinal data allow us to state, as we did previously in Figure 3, that girls and boys increase in total body $\mathrm{K}$ at the same rate in reference to height until about $130-140 \mathrm{~cm}$. when "taller" girls deviate from the common regression line with a decrease in slope. Forbes also observed that the slope for lean body mass and height growth in the adolescent female is less steep than

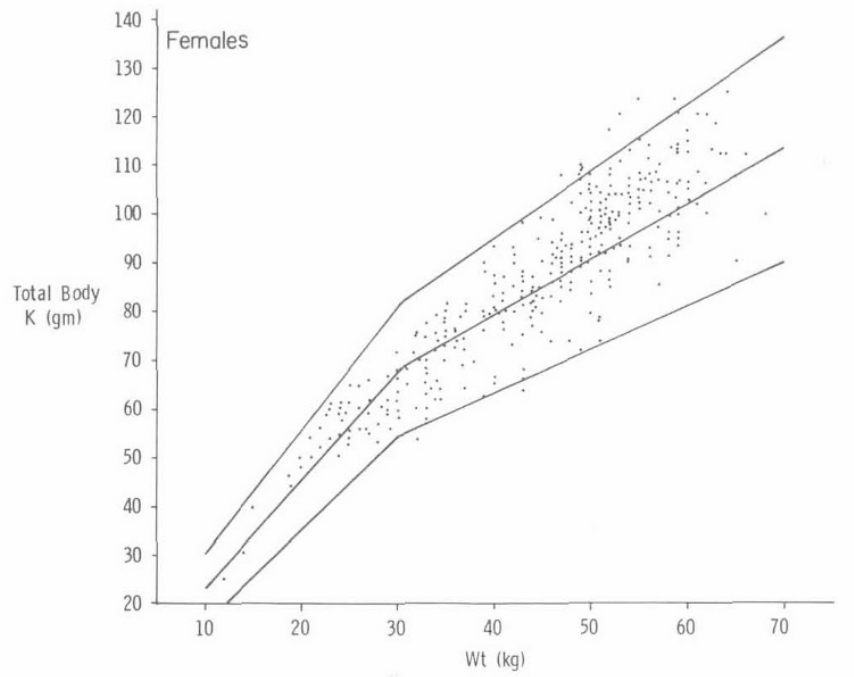

Fig. 5. Relationship between weight and total body potassium in girls. Annual measurements of the same 126 girls over a 4-5-year period compared with the regression lines for the mean and tolerance region for $68 \%$ of the population for total body potassium vs. weight for 230 girls aged 3-18 years from the data of Flynn et al. (2).

the male (4). Pierson et al. (9) separated females and males at age 14 in his height-K studies, with decreased $\mathrm{K}$ per $\mathrm{cm}$ in girls (9).

We have previously stated, as have other investigators ( $1-5$, 9) that total body K (or LBM) vs. height should be used as a standard in assessing body composition because it reflects changes associated with physiologic and endocrinologic changes occurring with puberty and may be more sensitive than weight in predicting growth. Yet, much published data is in reference to weight, perhaps because many pediatricians think in terms of age and weight in the medical care of children. In Figures 4 and 5 longitudinal weight and total body $\mathrm{K}$ measurements from this study are shown to agree with the previously published data (2).

\section{SUMMARY}

Measurements of total body $\mathrm{K}$ vs. height as well as total body $\mathrm{K}$ vs. weight over a 4-5-year period in the same children are in good agreement with previous cross-sectional observations of children aged 3-18 years.

\section{REFERENCES AND NOTES}

1. Cheek, D. B., editor: Human Growth: Body Composition Cell Growth, Energy and Intelligence (Lea \& Febiger, Philadelphia, 1968).

2. Flynn, M. A., Woodruff, C., Clark, J., and Chase, G.: Total body potassium in normal children. Pediat. Res., 6: 239 (1972).

3. Flynn, M. A., Murthy, Y., Clark, J., Comfort, G., Chase, G., and Bentley, A.: Body composition of Negro and white children. Arch. Environ. Health, 20;604 (1970).

4. Forbes, G.: Stature and lean body mass. Amer. J. Clin. Nutr., 27: 595 (1974).

5. Forbes, G.: Relation of lean body mass to height in children and adolescents. Pediat. Res., 6: 32 (1972).

6. Forbes, G.: Toward a new dimension in human growth. Pediatrics, 36: 825 (1965).

7. Friis-Hansen, B.: Body composition during growth. Pediatrics, 47: 264 (1971).

8. Malina, R. M.: Quantification of fat, muscle and bone in man. Clin. Orthoped., 65 (1969).

9. Pierson, R. N., Lin, D. H. Y., and Phillips, R. A.: Total-body potassium in health: Effects of age, sex, height, and fat. Amer. J. Physiol., 226: 206 (1974).

10. Partial support for the study was from the Agriculture Experiment Station and Medical Research Funds, University of Missouri-Columbia, Columbia, Mo.

11. Requests for reprints should be addressed to: M. A. Flynn, Ph.D., M757 Medical Center, Columbia, Mo. 6520I (USA).

12. Accepted for publication July 3, 1975. 